\title{
ANALISIS PERMINTAAN PUPUK UREA BERSUBSIDI DI PT. PUPUK KALTIM KOTA MATARAM
}

\section{ANALYSIS OF DEMAND FOR SUBSIDIZED UREA FERTILIZER IN PT. PUPUK KALTIM MATARAM CITY}

\author{
Nurmaya Khaeroni, Anwar, Siti Nurjannah \\ Program Studi Agribisnis Jurusan Sosial Ekonomi Pertanian Universitas Mataram \\ Email: nurmayakhaeroni15@gmail.com
}

\begin{abstract}
ABSTRAK
Penelitian ini bertujuan untuk : (1) Untuk mengetahui pengaruh harga pupuk urea bersubsidi, luas lahan, pendapatan petani, dan lama pendidikan petani terhadap permintaan pupuk urea bersubsidi di Kota Mataram. (2) Mengetahui elastisitas permintaan pupuk urea bersubsidi bagi petani di Kota Mataram. Penelitian ini menggunakan metode deskriptif. Penentuan lokasi kecamatan dilakukan dengan metode purposive sampling dengan pertimbangan bahwa Kecamatan Sandubaya memiliki jumlah penjualan pupuk urea bersubsidi terbanyak di Kota Mataram pada tahun 2018, dan penentuan lokasi kelurahan dilakukan juga secara purposive sampling dengan pertimbangan bahwa Kelurahan Dasan Cermen memiliki jumlah anggota kelompok tani terbanyak yang menggunakan pupuk urea bersubsidi. Penentuan responden ditentukan secara qouta sampling dengan rumus slovin. Jumlah responden masing-masing kelompok tani ditentukan secara proportional sampling, selanjutnyadua orang pengurus diambil secara purposive sampling dan anggota kelompok diambil secara random sampling. Jenis dan sumber data yang digunakan adalah primer dan sekunder. Hasil penelitian menunjukkan bahwa faktor yang berpengaruh secara nyata pada permintaan pupuk urea bersubsidi di Kota Mataram hanya luas lahan (X2). Elastisitas pendapatan didapatkan sebesar $((-2033833,58)<1)$, artinya derajat kepekaan pendapatan konsumen terhadap permintaan pupuk urea bersubsidi memiliki sifat permintaan inelastis.
\end{abstract}

Kata Kunci: Analisis Permintaan, Pupuk Urea Bersubsidi

\begin{abstract}
This research aims to: (1) To determine the effect of subsidized urea fertilizer prices, land area, farmers income, and length of farmers education on the demand for subsidized urea fertilizer in the Mataram City. (2) Knowing the elasticity of demand for subsidized urea fertilizer for farmers in the Mataram City. This research uses a descriptive method. Determination of sub-district location is done by purposive sampling method with the consideration that Sandubaya Subdistrict has the highest number of subsidized urea fertilizer sales in Mataram City in 2018, and the determination of the location of kelurahan is done also by purposive sampling with the consideration that Dasan Cermen Kelurahan has the highest number of farmer group members using subsidized urea fertilizer. Determination of respondents determined by qouta sampling with Slovin formula. The number of respondents in each farmer group is determined by proportional sampling, then two administrators are taken by purposive sampling and group members are taken by random sampling. The types and sources of data used are primary and secondary. The results showed that the factor that significantly affected the demand for subsidized urea fertilizer in the Mataram City was only the area of land (X2). The income elasticity is obtained ((-2033833.58) <1), meaning that the degree of sensitivity of consumer income to the demand for subsidized urea fertilizer has the nature of inelastic demand.
\end{abstract}

Keywords: Analysis of Demand, Subsidized Urea Fertilizer

Khaeroni, N., Anwar, dan Nurjannah, S.

Volume 29 Nomor 3 Desember 2019 


\section{PENDAHULUAN}

Indonesia adalah salah satu negara berkembang yang memiliki potensi alam yang melimpah luah, terutama dalam sektor pertanian. Pada sektor tersebut, salah satu cara pemerintah mengoptimalkannya yaitu dengan membuat kebijakan subsidi sarana produksi pertanian (benih, pupuk, pestisida), yang bertujuan membantu petani meningkatkan hasil produksi pertanian dengan biaya yang rendah. Agar tujuan tersebut dapat tercapai dengan baik, maka dalam pelaksanaannya pemerintah membangun suatu Badan Usaha Milik Negara yang bernama PT. Pupuk Indonesia (Persero) (Nurmala, dkk., 2012).

PT. Pupuk Kaltim merupakan salah satu perusahaan yang dibawahi oleh PT. Pupuk Indonesia yang berpusat di Kalimantan Timur dan sekarang sudah memiliki banyak Lini (gudang) di seluruh Indonesia, salah satunya di Lombok Barat, Provinsi NTB. Hal ini memudahkan pendistribusian pupuk bersubsidi terjangkau dan tersuplai dengan baik ke seluruh wilayah NTB khususnya di Kota Mataram, seperti yang ditunjukkan oleh Tabel 1 yang menunjukan data realisasi penjualan pupuk urea bersubsidi dibeberapa kecamatan di Kota Mataram (PT. Pupuk Kalimantan Timur, 2017).

Tabel 1 Data Realisasi Penjualan Pupuk Urea Bersubsidi di Kota Mataram Tahun 2014-2018 (dalam Ton)

\begin{tabular}{lllllll}
\hline \multirow{2}{*}{ No } & \multirow{2}{*}{ KECAMATAN } & \multicolumn{5}{c}{ TAHUN } \\
\cline { 3 - 6 } & & 2014 & 2015 & 2016 & 2017 & $\left.2018^{*}\right)$ \\
\hline 1 & Ampenan & 154,10 & 76,30 & 89,00 & 104,95 & 121,00 \\
2 & Cakranegara & 152,00 & 121,45 & 114,00 & 122,00 & 120,50 \\
3 & Mataram & 274,95 & 283,90 & 250,00 & 228,25 & 212,70 \\
4 & Sandubaya & 469,25 & 420,10 & 424,75 & 467,90 & 432,85 \\
5 & Sekarbela & 475,65 & 397,10 & 338,95 & 334,35 & 336,00 \\
6 & Selaparang & 136,15 & 150,90 & 136,00 & 131,75 & 100,10 \\
\hline \multicolumn{2}{l}{ TOTAL } & $1.662,10$ & $1.449,75$ & $1.352,70$ & $1.389,20$ & $1.323,15$ \\
\hline
\end{tabular}

Keterangan: *) Realisasi penjualan sampai dengan tanggal 19 November 2018

Sumber : PT. Pupuk Kalimantan Timur KP NTB (2018).

Berdasarkan Tabel 1, penjualan pupuk urea bersubsidi dari tahun 2014 sampai 2018 mengalami penurunan pada 6 kecamatan di wilayah Kota Mataram. Penurunan penjualan tersebut disebabkan oleh faktorfaktor yang mempengaruhi permintaan yaitu harga pupuk urea bersubsidi, luas lahan, pendapatan petani, dan lama pendidikan petani. Dilihat dari faktor-faktor tersebut, dapat diketahui seberapa besar elastisitas permintaan dari jumlah permintaan pupuk urea bersubsidi di Kota Mataram. Untuk mengetahuinya, maka telah dilakukan penelitian “Analisis Permintaan Pupuk Urea Bersubsidi di PT. Pupuk Kaltim Kota Mataram”.

Tujuan dari penelitian yaitu : (1) Untuk mengetahui pengaruh harga pupuk urea bersubsidi, luas lahan, pendapatan petani, dan lama pendidikan petani terhadap permintaan pupuk urea bersubsidi di Kota Mataram. (2) Untuk mengetahui elastisitas permintaan pupuk urea bersubsidi bagi petani di Kota Mataram.

\section{METODE PENELITIAN}

\section{Metode Penelitian}

Metode yang digunakan dalam penelitian ini adalah metode deskriptif. Menurut Nazir (2017), metode deskriptif merupakan suatu metode penelitian untuk membuat deskripsi atau menggambarkan: yaitu melukis secara sistematik, faktual dan akurat mengenai faktor-faktor, sifat-sifat serta hubungan antara fenomena yang diselidiki.

\section{Unit Analisis}

Unit analisis dalam penelitian ini adalah usahatani yang menggunakan pupuk urea bersubsidi dari PT. Pupuk Kalimantan Timur.

\section{Penentuan Daerah Sampel}

Penelitian ini berlokasi di Kota Mataram. Kota Mataram terdiri dari enam Kecamatan yaitu Kecamatan Ampenan, Kecamatan Cakranegara, Kecamatan Sandubaya, Kecamatan Sekarbela, Kecamatan Selaparang, dan Kecamatan Mataram. Penentuan sampel kecamatan dilakukan secara purposive sampling dengan pertimbangan bahwa Kecamatan Sandubaya memiliki jumlah penjualan pupuk urea bersubsidi terbanyak di Kota Mataram pada tahun 2018. Kecamatan Sandubaya terdiri dari tujuh kelurahan yaitu Kelurahan Abian Tubuh, Kelurahan Dasan Cermen, Kelurahan Mandalika, Kelurahan Babakan, Kelurahan Bertais, Kelurahan Turida, dan Kelurahn Selagalas. Penentuan sampel kelurahan dilakukan juga secara purposive sampling dengan pertimbangan bahwa Kelurahan Dasan Cermen memiliki jumlah anggota kelompok tani terbanyak yang menggunakan pupuk urea bersubsidi dari PT. Pupuk Kalimantan Timur. Kelompok tersebut adalah Kelompok Tani Taker Dirik, Kelompok Tani Purwasari dan Kelompok Tani Sumber Rezeki. 


\section{Penentuan Responden}

Responden dalam penelitiaan ini adalah anggota kelompok tani yang menggunakan pupuk urea bersubsidi dari PT. Pupuk Kalimantan Timur. Penentuan responden dilakukan secara qouta sampling yaitu sebanyak 32 responden dengan degree of error $15 \%$ dari populasi anggota kelompok tani yang berada di Kelurahan Dasan Cermen yang berjumlah 113 orang. Menurut Sugiyono (2018) qouta sampling adalah teknik menentukan sampel dari populasi yang mempunyai ciri-ciri tertentu sampai jumlah (kouta) yang diinginkan. Responden terdiri dari pengurus dan anggota kelompok. Dari masing-masing kelompok diambil dua orang pengurus secara purposive sampling dan anggota kelompok diambil secara random sampling. Salah satu metode yang digunakan untuk menetukan jumlah sampel adalah menggunakan rumus Slovin (Sevilla et al., 2007). Penentuan jumlah responden secara quota sampling dengan rumus slovin, sebagai berikut :

$n=\frac{N}{1+N e^{2}}$

Keterangan :

$\mathrm{n} \quad=$ kuota sampel

$\mathrm{N}=$ populasi

e2 = derajat eror (degree of error)

Dengan perhitungan sebagai berikut :

$n=\frac{113}{1+113 \times 0,15^{2}}$

$n=\frac{113}{1+113 \times 0,15^{2}}$

$n=\frac{113}{1+113 \times(0,0225)}$

$n=\frac{113}{3,5425}$

$n=32$

Penentuan jumlah responden masing-masing kelompok tani secara proportional sampling dengan perhitungan sebagai berikut :

1. Kelompok Tani Taker Dirik :

$\frac{25}{113} \times 32=7$ orang

2. Kelompok Tani Purwasari :

$\frac{30}{113} \times 32=9$ orang

3. Kelompok Tani Sumber Rezeki :

$\frac{58}{113} \times 32=16$ orang

Setelah dilakukan penentuan jumlah responden masing-masing kelompok tani, selanjutnya dari jumlah tersebut diambil pengurus secara purposive sampling yaitu diambil dua orang pengurus yang menjadi ketua dan sekretaris kelompok tani. Sisa dari pengurus tersebut menjadi responden untuk anggota kelompok tani yang diambil secara random sampling dengan undian, berikut perhitungannya :

1. Kelompok Tani Taker Dirik

Pengurus : 2 orang

Anggota : $7-2=5$ orang

2. Kelompok Tani Purwasari

Pengurus : 2 orang

Anggota : $9-2=7$ orang

3. Kelompok Tani Sumber Rezeki

Pengurus : 2 orang

Anggota : $16-2=14$ orang

Jenis dan Sumber Data

Jenis dan sumber data yang digunakan yaitu data primer dan data sekunder. Data primer adalah data yang diperoleh dari wawancara langsung dengan responden di daerah penelitian dengan berpedoman pada daftar pertanyaan yang telah dipersiapkan sebelumnya. Data sekunder adalah data yang diperoleh dari pustaka dan instansi yang ada kaitannya dengan penelitian ini seperti Kantor Pemasaran PT. Pupuk Kaltim KP NTB dan Kantor Puskud NTB. 


\section{Variabel dan Cara Pengukuran}

Variabel dan cara ukur yang digunakan dalam penelitian ini yaitu permintaan, harga pupuk urea bersubsidi, pendapatan petani, luas lahan, lama pendidikan petani, biaya produksi, jumlah produksi, harga jual produk, dan penerimaan

\section{Cara Pengumpulan Data}

Pengumpulan data dilakukan dengan menggunakan kuisioner, menurut Sugiyono (2018) kuesioner merupakan tehnik pengumpulan data yang dilakukan dengan cara menanyakan pernyataan tertulis kepada responden. Selain itu pengumpulan data juga dilakukan dengan merekam dan mencatat hal-hal yang diperlukan dari dokumen-dokumen yang ada di instansi-instansi terkait.

\section{Analisis Data}

\section{Mengetahui faktor-faktor yang mempengaruhi permintaan pupuk urea bersubsidi di PT. Pupuk Kaltim.}

Untuk mengetahui besarnya pengaruh faktor-faktor yang mempengaruhi permintaan pupuk urea bersubsidi di PT. Pupuk Kaltim untuk wilayah Kota Mataramdengan fungsi Cobb-Douglas. Soekartawi (1994) mendefinisikan fungsi Cobb-Douglas permintaan dengan menggunakan analisis regresi model Cobb-Douglas adalah suatu fungsi atau persamaan yang melibatkan dua atau lebih variabel, dimana variabel yang satu disebut dengan variabel dependen, atau dijelaskan (Y) dan yang lain disebut variabel independen, atau menjelaskan (Xi). Fungsi Cobb-Douglas dapat ditulis sebagai berikut :

$Y=\alpha X 1^{b 1} X 2^{b 2} X 3^{b 3} X 4^{b 4}+e i$

Untuk mempermudah pendugaan terhadap persamaan dapat diubah menjadi bentuk linier dengan cara melogaritmakan persamaan tersebut.

$\log Y=\log a+b 1 \log X 1+b 2 \log X 2+b 3 \log X 3+b 4 \log X 4+e i$

Dimana :

Y =Jumlah Permintaan Pupuk Urea Bersubsidi

a $\quad=$ Konstan

$\mathrm{X} 1=$ Harga Pupuk Urea Bersubsidi $(\mathrm{Rp} / \mathrm{kg})$

$\mathrm{X} 2=$ Luas Lahan $(\mathrm{Ha})$

$\mathrm{X} 3=$ Pendapatan Petani (Rp/musim panen)

X4 = Lama Pendidikan (Tahun)

b1- b4 = Koefisien Regresi variabel bebas X1 - X4

ei $\quad=$ Error

Rumusan Hipotesis, yaitu :

1. $\mathrm{H}_{0}: \mathrm{b}_{\mathrm{i}}=0$, Faktor harga pupuk urea bersubsidi, luas lahan, pendapatan petani, dan lama pendidikan tidak berpengaruh nyata terhadap permintaan pupuk urea bersubsidi.

2. $\mathrm{H}_{\mathrm{i}}: \mathrm{b}_{\mathrm{i}} \neq 0$, Faktor harga pupuk urea bersubsidi, luas lahan, pendapatan petani, dan lama pendidikan berpengaruh nyata terhadap permintaan pupuk urea bersubsidi.

3. $\mathrm{H}_{\mathrm{i}}$ : Tidak semua faktor $=0$

Kriteria pengujian untuk Uji F (Uji Serentak) dan Uji T (Uji Parsial) sebagai berikut :

1. Jika nilai sig $<0,05$; maka $\mathrm{H}_{0}$ ditolak,

2. Jika nilai sig $>0,05$; maka $\mathrm{H}_{0}$ diterima.

Hasil pendugaan pada fungsi Cobb-Douglas akan menghasilkan koefisien regresi dimana nilai koefisien regresi masing-masing variabel adalah besaran elastisitasnya.

\section{Mengetahui elastisitas permintaan pupuk urea bersubsidi bagi petani di Kota Mataram}

1. Untuk mengetahui elastisitas harga pupuk urea bersubsidi digunakan rumus elastisitas harga $\left(E_{d}\right)$. Koefisien elastisitas permintaan dihitung dengan menggunakan rumus dibawah ini: $E_{d}=\frac{\% \text { perubahan jumlah barang yang diminta }}{\% \text { perubahan harga }}$

2. Untuk mengetahui elastisitas pendapatan petani yang menggunakan pupuk urea bersubsidi digunakan rumus elastisitas pendapatan $\left(\mathrm{E}_{\mathrm{Y}}\right)$ berikut (Sjah, 2010) :

$E_{Y}=\frac{\% \text { perubahan jumlah barang yang diminta }}{\% \text { perubahan pendapatan }}$ 
Kriteria yang dipergunakan dalam elastisitas harga dan elastisits pendapatan adalah sebagai berikut :

1. Bila $E_{d} / E_{Y}=$ Tak terhingga disebut permintaannya elastisitas sempurna

2. Bila $E_{d} / E_{Y}>1$ disebut permintaannya elastis

3. Bila $E_{d} / E_{Y}=1$ disebut permintaannya unitary elastisitas/elastisitas satu

4. Bila $E_{d} / E_{Y}<1$ disebut permintaannya inelastic

5. Bila $\mathrm{E}_{\mathrm{d} /} \mathrm{E}_{\mathrm{Y}}=0$ disebut permintaannya inelastis sempurna

Pada elastisitas pendapatan, untuk mengetahui pendapatan petani maka perlu dicari melalui analisis biaya, analisis penerimaan, dan analisis pendapatan sebagai berikut:

1. Analisis Biaya

Menurut Soekartawi (1995) untuk menghitung besarnya biaya total (Total Cost) diperoleh dengan cara menjumlahkan biaya tetap (Fixed Cost/ FC) dengan biaya variabel (Variable Cost) dengan rumus:

$\mathrm{TC}=\mathrm{FC}+\mathrm{VC}$

Dimana:

$\mathrm{TC}=$ Total Cost $($ Biaya Total $)$

$\mathrm{FC}=$ Fixed Cost (Biaya Tetap Total)

$\mathrm{VC}=$ Variable Cost (Biaya Variabel)

2. Analisis Penerimaan

Menurut Soekartawi (1995) secara umum perhitungan penerimaan total usahatani (TR) adalah perkalian antara produksi yang diperoleh $(\mathrm{Y})$ dengan harga jual (Py) dan dinyatakan dengan rumus sebagai berikut:

$\mathrm{TR}=\mathrm{Py} . \mathrm{Y}$

Dimana:

$\mathrm{TR}=$ Total Revenue $($ Penerimaan Total $)$

Py $=$ Harga $Y$

$\mathrm{Y}=$ Produksi yang diperoleh dalam suatu usahatani

3. Analisis Pendapatan

Menurut Soekartawi (1995) pendapatan adalah selisih antara penerimaan (TR) dan biaya total (TC) dan dinyatakan dengan rumus:

$\mathrm{Pd}=\mathrm{TR}-\mathrm{TC}$

Dimana:

$\mathrm{Pd}=$ Pendapatan usahatani

TR $\quad=$ Total Revenue (Penerimaan Total)

TC $\quad=$ Total Cost (Biaya Total)

\section{HASIL DAN PEMBAHASAN}

Karakteristik Responden terakhir.

Karakteristik Responden terdiri dari Kelompok umur, jumlah tanggungan keluarga, pendidikan

\section{Umur Responden}

Berdasarkan hasil penelitian di Kelurahan Dasan Cermen, kelompok umur petani yang paling banyak menggunakan pupuk urea bersubsidi berada pada kisaran umur 15-64 tahun dengan jumlah responden sebanyak 24 orang (75\%), sedangkan kelompok umur petani yang paling sedikit menggunakan pupuk urea bersubsidi dari PT.Pupuk Kaltim berada pada umur $\geq 65$ tahun dengan jumlah responden sebanyak 8 orang $(25 \%)$.

\section{Tanggungan Keluarga Responden}

Berdasarkan hasil penelitian di Kelurahan Dasan Cermen menunjukkan bahwa kelompok tanggungan keluarga reponden yang paling banyak yaitu $\leq 3$ orang dengan jumlah responden sebanyak 24 orang $(75 \%)$, sedangkan jumlah anggota keluarga yang paling sedikit yaitu $\geq 6$ orang dengan jumlah responden sebanyak 1 orang $(3,1 \%)$.

\section{Tingkat Pendidikan Responden}

Berdasarkan hasil penelitian di Kelurahan Dasan Cermen menunjukkan bahwa tingkat pendidikan terakhir petani responden yang menggunakan pupuk urea bersubsidi paling banyak pada tingkatan pendidikan rendah yaitu Tamat SD-SMP dengan jumlah 24 orang $(75 \%)$, sedangkan rata-rata pendidikan terakhir petani responden yang paling sedikit pada tingkatan pendidikan tinggi yaitu S1 (Sarjana) dengan jumlah 1 orang $(3,1 \%)$. 


\section{Jumlah Permintaan Pupuk Urea Bersubsidi di PT. Pupuk Kaltim Kota Mataram}

Berdasarkan hasil penelitian di Kelurahan Dasan Cermen menunjukkan bahwa jumlah permintaan pupuk urea bersubsidi untuk 3 kelompok tani di Kelurahan Dasan Cermen yaitu pada kelompok tani Taker Dirik jumlah permintaan pupuk urea bersubsidi permusim tanamnya sebanyak $855 \mathrm{~kg}$. Kelompok Tani Purwasari jumlah permintaan pupuk urea bersubsidi permusim tanamnya sebanyak $1277.5 \mathrm{~kg}$. Kelompok tani selanjutnya yaitu kelompok tani Sumber Rezeki dengan jumlah permintaan pupuk urea bersubsidi permusim tanamnya yaitu sebanyak 2017,5 kg. Jumlah permintaan pupuk urea bersubsidi terbanyak pada kelompok tani Sumber Rezeki. Hal ini dikarenakan jumlah anggota kelompok tani Sumber Rezeki lebih banyak dibandingkan dengan kelompok tani yang lain dan juga luas lahan tanam petani pada kelompok tani Sumber Rezeki lebih luas.

\section{Faktor-Faktor yang Mempengaruhi Permintaan Pupuk Urea Bersubsidi di PT. Pupuk Kaltim Kota Mataram}

Pada penelitian ini menggunakan analisis regresi linier berganda dengan model Cobb-Douglas menggunakan aplikasi SPSS Statistic 22. Namun, untuk data harga pupuk urea bersubsidi tidak dapat dianalisis dengan model tersebut, karena data harga untuk semua responden sama. Ini disebabkan karena harga pupuk urea bersubsidi sudah ditetapkan oleh pemerintah, sehingga pengecer tidak dapat merubah harga pupuk urea bersubsidi. Berikut ini hasil Analisis Cobb-Douglas untuk variabel X2 (luas lahan) dan X3 (pendapatan petani), serta X4 (lama pendidikan) dari faktor-faktor yang mempengaruhi permintaan pupuk urea bersubsidi (Y) di PT Pupuk Kaltim Kota Mataram, tahun 2019.

Uji Signifikan Serentak (Uji-F)

Tabel 2 Hasil Analisis SPSS untuk Uji Signifikan Serentak (Uji-F)

\begin{tabular}{llrrrrr}
\hline \multicolumn{7}{c}{ ANOVAa } \\
\hline Model & Sum of Squares & Df & Mean Square & F & Sig. \\
\hline Regression & 2.545 & 3 & .848 & 56.639 & $.000 \mathrm{~b}$ \\
Residual & .419 & 28 & .015 & & \\
\multicolumn{1}{l}{ Total } & 2.965 & 31 & & & \\
\hline
\end{tabular}

a. Dependent Variable: Log_Jumlah Permintaan Pupuk Urea Bersubsidi

b. Predictors: (Constant), Log_Lama Pendidikan, Log_Luas Lahan, Log_Pendapatan Petani

Sumber: Data yang Sudah Diolah Dianalisis Tahun 2019

Pengujian signifikan Serentak (Uji-F) dilakukan untuk mengetahui apakah semua variabel independen secara bersama-sama (simultan) dapat berpengaruh terhadap variabel dependen, sehingga dapat diketahui variabel-variabel yang diduga mempengaruhi jumlah permintaan pupuk urea bersubsidi di PT. Pupuk Kaltim Kota Mataram. Tabel 2 menunjukkan hasil F-hitung memiliki probabilitas 0,000 ; dimana nilai probabilitas hasil output Anova yaitu 0.000 lebih kecil dibandingkan dengan taraf nyata 0,05 (sig.<0,05), maka $\mathrm{H}_{0}$ ditolak. Ini menunjukkan hasil variabel-variabel bebas (luas lahan, pendapatan petani, dan lama pendidikan), secara bersama-sama berpengaruh terhadap variabel terikat (jumlah permintaan pupuk urea bersubsidi di PT. Pupuk Kaltim Kota Mataram).

Uji Signifikan Parsial (Uji-T)

Tabel 3 Hasil Analisis SPSS untuk Uji Signifikan Parsial (Uji-T) Coefficientsa

\begin{tabular}{|c|c|c|c|c|c|}
\hline \multirow[b]{2}{*}{ Model } & \multicolumn{2}{|c|}{ Unstandardized Coefficients } & \multirow{2}{*}{$\begin{array}{r}\begin{array}{r}\text { Standardized } \\
\text { Coefficients }\end{array} \\
\text { Beta }\end{array}$} & \multirow[t]{2}{*}{$\mathrm{T}$} & \multirow[t]{2}{*}{ Sig. } \\
\hline & B & Std. Error & & & \\
\hline $1 \quad$ (Constant) & 3.452 & .667 & & 5.178 & .000 \\
\hline Log_Luas lahan & 1.082 & .095 & 1.005 & 11.413 & .000 \\
\hline Log_Pendapatan Petani & -.155 & .095 & -.148 & -1.644 & .111 \\
\hline Log Lama Pendidikan & .020 & .161 & .009 & .123 & .903 \\
\hline
\end{tabular}

Sumber: Data yang Sudah Diolah Dianalisis Tahun 2019

Tabel 3 menunjukkan variabel-variabel bebas yang berpengaruh secara parsial terhadap permintaan pupuk urea bersubsid di PT. Pupuk Kaltim Kota Mataram, sehingga diperoleh model persamaan fungsi CobbDouglas sebagai berikut :

$$
\mathrm{Y}=\log 3,452+1,082 \log \mathrm{X} 2-0,155 \log \mathrm{X} 3+0,020 \log \mathrm{X} 4
$$




\section{Konstanta}

Konstanta sebesar 3,452 menyatakan jika semua variabel bebas bernilai 0 maka jumlah permintaan pupuk urea bersubsidi di PT. Pupuk Kaltim Kota Mataram sebesar konstanta yakni sebesar 3,452 kg.Ini artinya permintaan pupuk urea bersubsidi akan berjumlah 3,452 kg apabila luas lahan, pendapatan petani dan lama pendidikan bernilai 0 .

\section{Pengaruh variabel luas lahan (X2) terhadap permintaan pupuk urea bersubsidi (Y)}

Hasil analisis dari persamaan fungsi Cobb-Douglas diatas, diperoleh nilai koefisien regresi untuk luas lahan (X2) sebesar 1,082. Nilai tersebut mengandung makna, jika variabel lain dianggap tetap (Ceteris paribus) maka setiap kenaikan luas lahan sebesar $1 \%$ akan menyebabkan peningkatan permintaan pupuk urea bersubsidi sebesar 1,082\%. Artinya, apabila terjadi kenaikan luas lahan, maka petani di Kota Mataram akan menambah jumlah penggunaan pupuk urea bersubsidi.

Pengujian dengan Uji-T, pada tabel 3 variabel X2 memiliki nilai signifikan sebesar 0,000 yang lebih kecil dari nilai probabilitas sebesar 0,05 (sig. < 0,05), maka $\mathrm{H}_{0}$ ditolak, sehingga dapat disimpulkan bahwa variabel X2 berpengaruh nyata terhadap variabel $\mathrm{Y}$ atau signifikan. Hal ini berarti luas lahan mempengaruhi permintaan pupuk urea bersubsidi. Hasil analisis ini terbukti dari ditetapkannya pembagian pupuk urea bersubsidi oleh pemerintah, untuk setiap petani yang termasuk ke dalam kelompok tani menerima $250 \mathrm{~kg}$ pupuk urea bersubsidi per $1 \mathrm{Ha}$ luas lahan sawah.

\section{Pengaruh variabel pendapatan petani (X3) terhadap permintaan pupuk urea bersubsidi $(Y)$}

Hasil analisis dari persamaan fungsi Cobb-Douglas diatas, diperoleh nilai koefisien regresi untuk pendapatan petani (X3) sebesar - 0,155. Nilai tersebut mengandung makna, jika variabel lain dianggap tetap (Ceteris paribus) maka setiap kenaikan pendapatan petani sebesar $1 \%$ akan menyebabkan penurunan permintaan pupuk urea bersubsidi sebesar $0,155 \%$. Artinya,jika terjadi kenaikan pendapatan petani, maka petani di Kota Mataram akan mengurangi jumlah penggunaan pupuk urea bersubsidi.

Pengujian dengan Uji-T pada tabel 3 variabel X3 memiliki nilai signifikan sebesar 0,111yang lebih besar dari nilai probabilitas sebesar 0,05 (sig. > 0,05), maka $\mathrm{H}_{0}$ diterima. Dapat disimpulkan bahwa variabel $\mathrm{X} 3$ tidak berpengaruh nyata terhadap variabel $\mathrm{Y}$ atau tidak signifikan.

\section{Pengaruh variabel lama pendidikan (X4) terhadap permintaan pupuk urea bersubsidi $(Y)$}

Hasil analisis dari persamaan fungsi Cobb-Douglas diatas, diperoleh nilai koefisien regresi untuk lama pendidikan (X4) sebesar 0,020. Nilai tersebut mengandung makna, jika variabel lain dianggap tetap (Ceteris paribus) kecuali harga pupuk urea bersubsidi, maka setiap kenaikan lama pendidikan petani sebesar $1 \%$ akan menyebabkan peningkatan permintaan pupuk urea bersubsidi sebesar 0,020\%. Artinya, jika terjadi kenaikan tingkat pendidikan petani, maka petani di Kota Mataram akan menambah jumlah penggunaan pupuk urea bersubsidi.

Pengujian dengan Uji-T diketahui pada tabel 3 variabel X4 memiliki nilai signifikan sebesar 0,903yang lebih besar dari nilai probabilitas sebesar 0,05 (sig. > 0,05), maka $\mathrm{H}_{0}$ diterima, sehingga dapat disimpulkan bahwa variabel $\mathrm{X} 4$ tidak berpengaruh nyata terhadap variabel $\mathrm{Y}$ atau tidak signifikan.

Uji $R^{2}$ (Koefisien Determinasi)

Tabel 4 Hasil Analisis SPSS untuk Uji Koefisien Determinasi (Uji R²)

\begin{tabular}{lllll}
\hline \multicolumn{5}{c}{ Model Summary } \\
\hline Model & $\mathrm{R}$ & $\mathrm{R}$ Square & Adjusted R Square & Std. Error of the Estimate \\
\hline 1 & $.927 \mathrm{a}$ & .859 & .843 & .12239 \\
\hline
\end{tabular}

a. Predictors: (Constant), Log_Lama Pendidikan, Log_Luas Lahan, Log_Pendapatan Petani

Sumber: Data yang Sudah Diolah Dianalisis Tahun 2019

Tabel 4 menunjukkan bahwa besarnya persentase pengaruh semua variabel independen terhadap nilai variabel dependen dapat diketahui dari besarnya koefisien determinasi (R2), sebesar 0.859artinya bahwa 85,9\% perubahan nilai variabel jumlah permintaan pupuk urea bersubsidi di PT Pupuk Kaltim Kota Mataram dipengaruhi oleh semua variabel independen (luas lahan (X2), Pendapatan petani (X3), dan lama pendidikan (X4)).Sisanya 14,1\% dipengaruhi oleh sebab-sebab yang lain di luar model.

\section{Elastisitas Permintaan Pupuk Urea bersubsidi}

\section{Elastisitas Harga terhadap Permintaan Pupuk Urea Bersubsidi}

Elastisitas harga merupakan perbandingan antara persentase perubahan jumlah barang yang diminta dengan persentase perubahan harga. Perhitungan elastisitas harga pupuk urea bersubsidi, digunakan rumus 
elastisitas harga (Ed), namun pada hasil penelitian menggunakan SPSS Statistic 22, tidak ditemukan hasil coefficients harga pupuk urea bersubsidi yang akan menjadidelta $\mathrm{P}(\Delta \mathrm{P})$, karena harga pupuk urea bersubsidi tidak bisa dianalisis. Hal ini disebabkankarena harga pupuk urea bersubsidi untuk semua responden sama, sehingga tidak dapat diketahui elastisitas harga terhadap permintaan pupuk urea bersubsidi.

\section{Elastisitas Pendapatan terhadap Permintaan Pupuk Urea Bersubsidi}

Elastisitas pendapatan merupakan perbandingan antara persentase perubahan jumlah barang yang diminta dengan persentase perubahan harga. Perhitungan elastisitas pendapatan terhadap pupuk urea bersubsidi digunakan rumus elastisitas pendapatan (EY). Hasil penelitian menggunakan SPSS Statistic 22, menunjukkan hasil coefficients pendapatan petani yang akan menjadi delta $\mathrm{Y}(\Delta \mathrm{Y})$ yaitu $-0,155$ dan coefficients permintaan pupuk urea bersubsidi yang akan menjadi delta $\mathrm{Q}(\Delta \mathrm{Q})$ yaitu 3,452. Diketahui rata-rata permintaan pupuk urea bersubsidi per musim panen $(\mathrm{Q})$ sebesar 133,59. Selanjutnya, untuk rata-rata pendapatan petar. im panen (Y) yaitu 12.200.604,57.

Hasil perhitungan menunjukkan bahwa elastisitas pendapatan sebesar $(-2033833,58)$ kurang dari 1 (($2033833,58)<1)$. Hal ini berarti derajat kepekaan pendapatan konsumen terhadap permintaan pupuk urea bersubsidi memiliki sifat permintaan inelastis, artinya adanya perubahan pendapatantidak berpengaruh terhadap jumlah permintaan pupuk urea bersubsidi.

\section{KESIMPULAN DAN SARAN}

\section{Kesimpulan}

Berdasarkan hasil analisis penelitian ini, penulis dapat mengambil kesimpulan yaitu sebagai berikut :

1. Secara statistik hanya luas lahan (X2) yang berpengaruh nyata atau signifikan terhadap permintaan pupuk urea bersubsidi di PT. Pupuk Kaltim Kota Mataram. Kemudian untuk pendapatan petani(X3) dan lama pendidikan (X4) tidak berpengaruh nyata atau tidak signifikan terhadap permintaan pupuk urea bersubsidi di PT. Pupuk Kaltim Kota Mataram, sedangkan untuk harga pupuk urea bersubsidi (X1) tidak dapat dianalisis karena memiliki data yang sama atau tidak ada perfect competition pada data variabel yang menjadi syarat untuk melakukan analisis Cobb-Douglas.

2. Elastisitas harga terhadap permintaan pupuk urea bersubsidi tidak dapat dianalisis, karena koefisien harga pupuk urea bersubsidi yang akan menjadi delta $\mathrm{P}(\Delta \mathrm{P})$ tidak ditemukan. Akan tetapi, untuk elastisitas pendapatan terhadap permintaan pupuk urea bersubsidi dapat dianalisis. Hasil dari elastisitas pendapatan didapatkan $((-2033833,58)<1)$, artinya derajat kepekaan pendapatan konsumen terhadap permintaan pupuk urea bersubsidi memiliki sifat permintaan inelastis, atau adanya perubahan pendapatan tidak berpengaruh terhadap jumlah permintaan pupuk urea bersubsidi.

Saran

Berdasarkan kesimpulan yang diperoleh maka penulis mengajukan saran untuk peningkatan dan kesejahteraan petani di Kota Mataram yaitu diharapkan kepada pemerintah membantu dalam menambah penyediaan jatah pupuk urea bersubsidi untuk setiap petani dalam kelompok tani. Hal ini karena kebanyakan petani masih kekurangan pupuk urea bersubsidi, sehingga untuk menutupinya mereka harus membeli pupuk urea nonsubsidi yang jauh lebih mahal.

\section{DAFTAR PUSTAKA}

Nazir, M. 2017. Metode Penelitian. Ghalia Indonesia. Jakarta.

Nurmala, T., dkk. 2012. Pengantar Ilmu Pertanian. Graha Ilmu. Yogyakarta.

Sugiyono. 2018. Metode Penelitian Kuantitatif, Kualitatif, R\&D. CV. Alfabeta. Bandung.

Sevilla, Consuelo G. et al. 2007. Research Methods. Rex Printing Company. Quezone City

Sjah, T. 2010. Ekonomi Pertanian. Mataram University Press. Mataram.

Soekartawi. 1994. Teori Ekonomi Produksi dengan Pokok Bahasan Analisis Cobb-Douglas. PT. Raja Grafindo Persada. Jakarta.

Soekartawi. 1995. Analisis Usahatani. UI Press. Jakarta

PT. Pupuk Kalimantan Timur. 2017. Profil Bisnis. https://www.pupukkaltim.com. Diakses 12 Desember 2018.

PT. Pupuk Kalimantan Timur KP NTB. 2018. Realisasi Penjualan Pupuk Urea Bersubsidi di Kota Mataram Tahun 2014-2018. PT. Pupuk Kalimantan Timur KP NTB 